\title{
A comunidade como espaço de produção de saúde mental: contribuições da Psicologia Comunitária ao processo de desinstitucionalização ${ }^{1}$
}

\section{The community as production space for mental health: contributions of community psychology to the process of desinstitutionalization}

\section{Dayane Silva Rodrigues*}

Secretaria da Criança do Governo do Distrito Federal - GDF, Brasília, Distrito Federal, Brasil

\section{Maria Aparecida Alves Sobreira de Carvalho**}

Instituto Federal de Educação, Ciência e Tecnologia da Paraíba- Campus SousaIFPB, Sousa, Paraíba, Brasil

\section{Verônica Morais Ximenes***}

Universidade Federal do Ceará - UFC, Fortaleza, Ceará, Brasil

\begin{abstract}
RESUMO
No contexto de implantação da reforma psiquiátrica brasileira, importantes conquistas foram obtidas com a proposição de serviços substitutivos ao manicômio. Contudo, a desinstitucionalização da loucura ultrapassa a esfera da desospitalização e se constitui, ainda, em um desafio cada vez mais atual. Para avançar nessa problemática, a comunidade tem sido crescentemente destacada como espaço potencialmente rico na produção coletiva da saúde mental. Contudo, observam-se poucos questionamentos e discussões quanto às concretas possibilidades terapêuticas desse lugar. Nesse sentido, a Psicologia Comunitária traz alguns aportes que permitem refletir acerca do modo de entendimento desse termo e dos processos comunitários em geral. Assim, a proposta deste artigo é situar algumas contribuições da Psicologia Comunitária para fomentar a desinstitucionalização nos próprios serviços de saúde mental e para além destes.
\end{abstract}

Palavras-chave: Desinstitucionalização; Saúde mental; Psicologia Comunitária; Comunidade.

\begin{abstract}
In the context of implementation of psychiatric reform in Brazil, important achievements were obtained with the proposition of alternative services to asylum. However, the desinstitutionalization of madness exceeds the limits of unospitalization and is also a growing challenge today. To advance this issue, the community has been increasinglyhighlighted as a potentially rich space in producing collective mental health. However, there are a few questions and discussions about the specific therapeutic possibilities of this
\end{abstract}


place. In this sense, community psychology has some contributions that allow to reflect about the understanding of this term and community processes in general. Thus, the purpose of this article is to set some contributions of community psychology to promote the desinstitutionalization in the own mental health services and beyond.

Keywords: Desinstitutionalization; Mental health; Community Psychology; Community.

\section{I ntrodução}

O processo de desinstitucionalização é aquilo que eu disse antes, ele continua no território, ele continua na comunidade, ou ainda, se torna mais importante na comunidade: o processo de desinstitucionalização, do meu ponto de vista, continua a ser a estratégia terapêutica na comunidade [...] (ROTELLI, 1994, p. 154).

A luta do movimento de Reforma Psiquiátrica brasileiro garantiu a conquista de alguns avanços introduzidos pelas políticas de saúde nesse setor, na proposição de um sistema de serviços de base comunitária, não institucionalizado. Todavia, apesar do ganho obtido com a criação de modelos substitutivos ao tradicional manicômio, é notório o descompasso entre o que se defende em tese e a prática cotidiana dos serviços, tal como verificamos em diversos estudos que discutem os modos de atuação e a efetividade dos CAPS (ALVERGA; DIMENSTEIN, 2006; ONOCKO-CAMPOS; FURTADO, 2006; PAIVA, 2003; AMARANTE, 2003).

Acerca dos obstáculos ao processo de desinstitucionalização da loucura, destaca-se o risco da redução da reforma a ações de desospitalização. Autores como Dimenstein e Amorim (2009); Amarante (2003); Antunes e Queiroz (2007), Rotelli (2001), entre outros trabalham com a possibilidade de que tal redução se resumiria à saída dos usuários dos hospitais psiquiátricos, sem a real desmontagem desses. Nesse caso, não se trata apenas do deslocamento da atenção em saúde mental para serviços substitutivos territoriais integrados à rede de saúde mais ampla, mas sim o desmantelamento completo de uma cultura manicomial, que institucionaliza a loucura, esteja esta dentro ou fora do hospital.

Amarante (1996) destaca ainda que não existe consenso quanto às distintas concepções que a palavra desinstitucionalização pode assumir. Nesse caso, para cada possibilidade de conotação do termo, encontramos também diferentes projetos de reforma em saúde mental, que sustentam tal definição. Assim, segundo o autor, o que

efetivamente demarca uma real distinção entre os projetos de reforma [...] é a forma do lidar prático e teórico da desinstitucionalização, conceito este que sofre metamorfose 
substancial e que abre novas possibilidades para o campo da reforma (AMARANTE, 1996, p. 26).

No Brasil, a III Conferência Nacional de Saúde Mental (BRASIL, 2002), ocorrida em 2001, assumiu como desafio para efetiva superação do modelo asilar a implantação de uma política de desospitalização com concomitante construção de uma rede substitutiva, que assegure assistência integral e de qualidade, de acordo com os princípios da Reforma Psiquiátrica. Contudo, no relatório apresentado pelo Ministério da Saúde, 15 anos depois de Caracas $^{2}$, em 2005, a Coordenação de Saúde Mental do Ministério da Saúde assumiu que um grande número de pessoas ainda precisava de uma rede de cuidados em saúde mental de forma densa, diversificada e efetiva. Admitiu também a persistência do modelo hospitalocêntrico, concentrador de recursos, e a baixa cobertura da rede de saúde mental. Atentou, ainda, para a dificuldade de garantir o acesso e a qualidade do atendimento a todas as regiões, bem como para a dificuldade na formação de recursos humanos capazes de superar o paradigma da tutela do louco e da loucura.

Diante dessas observações e do questionamento recorrente do papel da Psicologia na superação do desafio apresentado, tivemos interesse em problematizar as contribuições que a Psicologia Comunitária da América Latina ${ }^{3}$ (GÓIS, 2005; MONTERO, 2003; 2004; 2006; LANE, 1996) pode oferecer ao processo de desinstitucionalização proposto pelas políticas de atenção à saúde mental atuais. Segundo Góis ${ }^{4}$ (2005, p. 51), "a psicologia comunitária é uma área da Psicologia Social da Libertação", que nasce na América Latina e diferencia-se da Psicologia Comunitária da Europa e dos Estados Unidos, justamente por sua forte aproximação com os movimentos sociais e por sua preocupação com a superação dos problemas sociais vivenciados por seu povo. Nesse sentido, apesar da polifonia de discursos e das divergências conceituais e metodológicas que apresenta, tal psicologia oferece importantes aportes que permitem refletir sobre o modo de entendimento dos processos comunitários, bem como sugere indícios de como podemos fomentar a desinstitucionalização para além dos serviços de saúde mental.

Os impasses verificados na idéia de conquista de uma reforma mais contundente, que acima foram descritos, são apresentados de modo a evidenciar uma perspectiva de desafio permanente em que se encontra o processo de produção da saúde mental. Neste artigo, almejamos refletir acerca de possíveis contribuições que a Psicologia Comunitária pode oferecer à superação de algumas dificuldades principais. Para tanto, elegemos dois conceitos discutidos por autores e profissionais da área como motes de reflexão acerca da construção coletiva dessa saúde, quais sejam, a saber: a participação 
comunitária (GÓIS, 2005, 2008; VIEIRA, 2008) e a problematização da realidade (MONTERO, 2006; GÓIS, 2005).

A princípio, apresentaremos a trajetória de evolução do termo desinstitucionalização em Saúde Mental, com o intuito de situar a construção processual da reforma ocorrida nesse setor e os entraves que se põem na atualidade para o rompimento com modelos de práticas asilares.

\section{A desmontagem do manicômio e o desafio da desinstitucionalização da loucura}

Barros (1994) coloca que, após as duas grandes guerras mundiais, travou-se um processo de reestruturação socio-institucional das sociedades européias e americanas, no qual os governos passaram a responsabilizar-se - oficialmente - pelos problemas sociais. 0 surgimento dessas idéias de caráter reformistas ocorreu diante do aumento do custo de vida, das mortes em massa, da fome e de eventos decorrentes do envolvimento na II Guerra Mundial e da fragilização sócio-econômica, na crise de 1924. Neste período, aconteceu uma retomada da valorização da vida como um incremento da própria valorização do direito à saúde. De acordo com Menezes e Yasui (2009), surge a implantação do primeiro seguro-saúde em 1942, com o Plano Beveridge, na Inglaterra, que serviu de exemplo para a reforma de vários sistemas de saúde, inclusive o americano.

Como um dos desdobramentos de tal fato, surge a ideia da desospitalização, fundamentada na crítica aos hospitais psiquiátricos. Isso porque, no contexto pós-guerra, não se admitia a realidade violenta dos asilos. Dessa impossibilidade, surge, segundo Menezes e Yasui (2009), a psiquiatria preventiva ou comunitária americana, as comunidades terapêuticas na Inglaterra e a psiquiatria institucional e a psiquiatria de setor na França. Já o conceito de desinstitucionalização, surge um pouco mais tarde, na década de 1960, nos Estados Unidos, sob o comando do governo Kennedy, como "alta" dos pacientes psiquiátricos e sua reinserção na comunidade. Segundo Amarante (1996, p. 17), esta proposta "reporta à Psiquiatria um campo epistêmico que delineia o 'ideal da saúde mental' [...] e edifica o ideal da ausência das doenças mentais no meio social".

A desospitalização pretendida, no período citado, não pressupunha a criação de novos serviços, não discutia o papel hegemônico e centralizador do hospital psiquiátrico, tampouco questionava a própria psiquiatria como campo do saber que se fundamenta historicamente no diagnóstico e na exclusão da loucura. Por essa razão, Amarante (1992) categoriza este momento como fundamentado no modelo preventivo-comunitário, baseado na 
história natural das doenças de Caplan. Esta pressupõe a linearidade no desenvolvimento da saúde-doença e a existência de uma evolução histórica da apresentação das doenças no tempo e no espaço, tendo a estatística como grande instrumento de avaliação.

O modelo preventivista foi adotado pela OPS/OMS, EUA e países do 3o Mundo, estabelecendo, como prioridade nas ações de saúde mental, a promoção da saúde mental, o encurtamento da duração dos transtornos mentais e a minimização da deterioração resultante desses transtornos. O que se viu, a partir desta "nova" política, foi a saída do paciente do hospital psiquiátrico sem articulação com outros serviços, continuando a viver sem condições de exercer os seus direitos. Houve aumento dos ambulatórios de saúde mental, com conseqüente crescimento da demanda ambulatorial e hospitalar.

Oliveira e Alesi (2005) referem que a desospitalização em nada modifica a definição de objeto, objetivos e instrumentos de intervenção previstos no modelo médico psiquiátrico tradicional. A Reforma Psiquiátrica não pode ser compreendida como um rearranjo administrativo da rede de assistência, pois prédios novos e serviços com portas abertas não garantem projetos terapêuticos que respeitem a cidadania das pessoas com transtornos mentais. 0 processo de desinstitucionalização preconizado pela Reforma Psiquiátrica brasileira vai além da desospitalização.

A reforma brasileira é fortemente influenciada pelo referencial teórico e prático promovido pela Psiquiatria Democrática italiana, que surgiu no fim da década de 1960, sob a influência de Franco Basaglia. Este autor propôs uma nova maneira de lidar com a loucura, na qual o hospital psiquiátrico é considerado um instrumento de repressão e controle, que produz homens institucionalizados "homem imóvel, sem objetivo, sem futuro, sem um interesse, um olhar, uma expectativa, uma esperança para a qual apontar" (BASAGLIA, 2005, p. 27). Afirmou a necessidade de destruição das normas que regulamentam a dependência pessoal das pessoas com transtornos mentais, possibilitando a reconstrução de suas vidas nas bases jurídicas e econômicas, como espaços indispensáveis para a sua colocação no circuito das trocas sociais, reestabelecendo sua condição de membro do corpo social. Neste espaço social, redefinem-se as relações de poder:

as situações de "crise", não mais redirecionadas para dentro do sujeito que é seu portador, reabrem-se como crises entre os níveis de poder, entre interesses sociais, entre instituições e níveis institucionais, requerendo - por parte do técnico - uma mediação radicalmente nova (BASAGLIA, 2005, p. 249).

Amarante (1994) compreende a desinstitucionalização como desconstrução de saberes, discursos e práticas psiquiátricas que 
sustentam a loucura, reduzida ao signo da doença mental, e reforçam a instituição hospitalar. Busca a desconstrução de técnicas e conceitos centrados na doença, podendo construir outras concepções de saúde, da doença e do terapêutico, produzindo espaços sociais que tornem possível a ausência do manicômio.

Segundo Rotelli (2001), para que ocorra a desinstitucionalização, é necessária a desmontagem da cultura e da estrutura psiquiátrica que separou a doença da existência do sujeito, dando maior ênfase ao diagnóstico e ao sintoma, do que a sua experiência concreta e as relações que estabelece no corpo social. Ele afirma que o primeiro passo para a desmontagem desta lógica de exclusão é a renuncia à perseguição da cura, tendo como objeto da atenção a sua existênciasofrimento em suas possibilidades de vivenciar novos papéis sociais, novas oportunidades e possibilidades.

Para a desmontagem da lógica manicomial, Rotelli (2001) apresenta a necessidade de criação de laboratórios e não de ambulatórios, definindo como laboratório um lugar de produção de cultura, de trabalho, de intercâmbio e de relações entre artistas, artesãos, pessoas doentes ou não. Ele entende que a Saúde mental passa a ser compreendida não mais a partir de parâmetros de bem estar, definidos desde princípios biomédicos e regulados pelo Estado, mas como produção da vida possível e com sentido para os sujeitos em suas singularidades nos diferentes espaços de sociabilidade e solidariedade em que circulam.

Ainda sobre o assunto da desinsticionalização, Machado e Lavrador (2001) alertam que apesar dos vários avanços identificados na Reforma Psiquiátrica brasileira ainda persistem nos serviços de saúde mental e na vida cotidiana, o que chamam "desejos de manicômio" que são desejos de dominar, de subjugar, de classificar, de hierarquizar, de oprimir e controlar. Estes desejos atravessam o processo social e se fazem presente nas práticas e concepções no campo da saúde mental, sendo necessário criarmos espaço para a desrazão. Desta forma, poderíamos trabalhar na perspectiva de uma emancipação que vá além da social, passando a ser política, cultural e pessoal, que possibilite "o não-enclausuramento de tantas formas de existência banidas do convívio social; que passe a encampar todas as esferas e espaços sociais; que permita um olhar mais complexo que o generalizante olhar do igualitarismo; e busque a convivência tolerante com a diferença" (ALVERGA; DIMENSTEIN, 2006, p. 302).

A III Conferência Nacional de Saúde Mental (BRASIL, 2002) aponta que para fortalecer a desinstitucionalização é necessário que a rede de serviços de saúde mental tenha modalidades diversificadas de atenção, integradas à rede básica territorializada, contemplando ações referentes às áreas de trabalho, moradia e educação. "O serviços devem ser estruturados de forma descentralizada, integrada 
e intersetorial, de acordo com a necessidade dos usuários, visando garantir o acesso universal, humanizado e de qualidade" (p. 38).

A conferência também aponta como necessidade a reorganização da rede de atenção integral à saúde mental, a partir da ênfase na atenção básica, entendendo esta como um conjunto de unidades e ações articuladas em um território, sob o eixo do acolhimento, vínculo e heterogeneidade. Portanto, para garantir a territorialidade das ações, os serviços de saúde mental localizam-se em uma comunidade específica, porém muitas vezes atendendo a uma demanda referenciada por um bairro inteiro, ou por um município de pequeno porte. Dessa forma, convém indagarmos: quando falamos que o foco do serviço deve estar na comunidade, a qual conceito de comunidade estamos nos referindo? Como compreendemos as relações presentes no modo de vida de seus moradores? O que a comunidade tem a ver com a desinstitucionalização?

\section{A comunidade como espaço de produção da saúde mental.}

A complexidade crescente das relações sociais nas grandes metrópoles tem tornado o conceito de comunidade controverso e questionável. Segundo Pereira (2001), o termo pode carregar em si distintas acepções; uma delas seria aquela que dissemina "[...] a fantasia da unidade, da uniformidade, da ilusão, da perspectiva dos elementos serem profunda e absolutamente solidários, cooperativos e coesos." (p. 146). Nesse sentido, comunidade assume a conotação de estrutura unificadora, sem conflitos e com uma história de unidade comum. Na mesma perspectiva o teórico Zygmunt Bauman (2003) ancora suas críticas, chegando a defender que "'Comunidade' é nos dias de hoje outro nome do paraíso perdido - mas a que esperamos ansiosamente retornar, e assim buscamos febrilmente os caminhos que podem levar-nos até lá" (p. 9).

Em outra leitura do termo, poderíamos encontrar teóricos que defendem uma noção de comunidade na qual caberiam elementos como a diversidade, a singularidade e o conflito. Nessa ótica, a autora Sawaia (1996) refuta a conotação de comunidade como unidade consensual, quando afirma que esta "deve oferecer um espaço total de atitudes particulares" (p. 38). Na mesma linha de pensamento, encontramos a definição de Góis (2008), a qual pressupõe a comunidade como

[...] o lugar de moradia, de permanência estável e duradoura, de crescimento, de orientação e proteção da individualidade [...] apresenta um processo sociopsicológico próprio, cheio de contradições, antagonismos e interesses comuns que servem de construção e orientação das ações 
dos moradores em relação ao próprio lugar e à sua inserção no conjunto da sociedade (p. 85).

A despeito da polêmica em torno do tema, observa-se um movimento de efervescente discussão acerca da ideia de que a dita "comunidade" seria uma forma de organização societal enormemente potencializadora do desenvolvimento humano, um lugar privilegiado de interação e vinculação dos sujeitos. Portanto, lócus principal de atuação das políticas públicas atuais, principalmente a partir da década de mil novecentos e oitenta.

No campo das políticas de saúde, o termo comunidade ganhou progressivo destaque, desde o momento em que a crise de financiamento do modelo centrado na doença e a complexificação do conceito de saúde impulsionaram a necessidade de atuações mais preventivas. A partir de então, salienta-se a pertinência da responsabilização coletiva pela produção e cuidado da saúde e a crença no poder comunitário de tomada de decisões quanto às suas próprias questões de saúde-doença.

Acerca da discussão sobre a incorporação das ideias preventivistas em saúde, Lancetti (1989) afirma que a prevenção como prática foi importada dos Estados Unidos e outros países pela OMS e repassada com ares de modernidade e avanço com relação ao modelo da psicologia e psiquiatria individual e clínica. Assim, a prevenção acabou por se constituir não como uma prática única, mas sob vários modos como a medicina social, a psiquiatria moral e a psiquiatria preventiva. Além disso, as composições históricas no Brasil mostram não uma cronologia sucessiva que componha nossa saúde mental, mas uma mistura de modelos. Contudo, indaga o autor a respeito de como se daria e a que consistiria o progresso das ideias preventivistas, se "quando entendemos a saúde como emancipação do usuário e do trabalhador não tem mais sentido discriminar cura de prevenção, não tem mais sentido o vetor progresso, porque a manicomialização das instituições não é mais superável nem melhorável" (LANCETTI, 1989, p. 88).

Ainda no rumo desse mesmo movimento de valorização da soberania do poder local, a Carta de Otawa, de 1986, representa um marco legal que traz à tona a questão da promoção e institucionaliza a importância das comunidades nas esferas do planejamento, da gestão e da implementação de um sistema de saúde. O documento define a promoção da saúde como, justamente, "o processo de capacitação da comunidade para atuar na melhoria da sua qualidade de vida e saúde, incluindo uma maior participação no controle deste processo" (WHO, 1986).

Ao transferirmos a tônica do debate da Reforma Sanitária para a Reforma Psiquiátrica, constatamos que, em 1979, o psiquiatra italiano Franco Basaglia já discutia 0 processo de 
desinstitucionalização do aparato psiquiátrico e também defendia a perspectiva da ênfase no potencial comunitário de reabilitação. Contudo, nesse contexto de discussão sobre a comunidade como o novo espaço de intervenção em saúde mental, também houve espaço para que autores como Birman e Costa (1994) indagassem sobre a ideia de comunidade como uma totalidade homogênea. Nesse sentido, os teóricos reconhecem um equívoco em definir que os recursos institucionais e humanos da comunidade podem somar-se ao esforço da psiquiatria em prevenir, curar e reabilitar os pacientes psiquiátricos. Isso porque:

\begin{abstract}
Para que os indivíduos pertencentes a uma determinada comunidade participem de um projeto comum é necessário que tal projeto seja um objetivo social consensualmente importante. Ora, nenhum dado sociológico, antropológico, psicológico ou histórico permite-nos afirmar que, no Brasil, o interesse pela saúde mental satisfaça essa exigência. Nas modernas comunidades brasileiras nem os valores são comuns, nem as representações que os indivíduos têm de suas necessidades psíquicas são homogêneas (BIRMAN; COSTA, 1994, p. 62).
\end{abstract}

Nesse momento de redescoberta da comunidade, mesmo com toda a polêmica em torno de seu conceito, ganham força os movimentos de luta e defesa da construção de uma saúde mental de base comunitária e o movimento de psiquiatria social preventiva, os quais se relacionam com a origem e o desenvolvimento da psicologia comunitária, como veremos a seguir.

\title{
4 Interfaces entre o Movimento de Saúde Mental Comunitária e a Psicologia Comunitária
}

A psicologia comunitária tem sua origem calcada nos movimentos de psiquiatria social preventiva, especialmente nos Estados Unidos e na Europa, por volta da década de 1960. Nesses lugares, segundo Góis (2005), o surgimento dessa área está ligado à ampliação da saúde mental ao âmbito comunitário, quando se passou a considerar a prevenção, a promoção e o potencial de participação da comunidade como fundamentais. Montero (2004, p. 75,) coaduna com tal pensamento, quando afirma que: "Se revisarmos a gênese da psicologia comunitária, vemos que deriva de vários campos que a marcam profundamente: o psicossocial, o clínico, o educativo e, em particular, o movimento de saúde mental comunitário [...]". ${ }^{5}$

Arendt (1997) afirma ainda que, embora os primeiros passos da disciplina tenham sido dados na Europa e Estados Unidos, é na América Latina que ela ganha contornos característicos. O autor, 
citando Wiesenfeld e Sánchez (1991), sintetiza um conjunto de condições que teriam forjado seu surgimento nesse lugar. Estas estariam relacionadas com três elementos fundamentais. O primeiro seria a crítica a um conhecimento importado e descontextualizado produzido pela psicologia social tradicional, o segundo seria a emergência de movimentos sociais de base comunitária e o terceiro ponto teria sido a influência do pensamento de Paulo Freire e Fals Borda, introdutores da metodologia da pesquisa-ação.

No Brasil, ao mesmo tempo e com os mesmos fatores que se construía uma concepção de saúde mental de base comunitária, também se forjava uma psicologia mais voltada para a comunidade. Sánchez Vidal (1991, apud Góis 2005) comenta acerca do nascimento histórico de um movimento comunitário na década de 1960, que reverberou amplamente para diversas disciplinas, fazendo com que estas repensassem seus fazeres e se voltassem para as comunidades. Nesse escopo, encontramos o movimento de saúde mental comunitária, a pedagogia da libertação, a teologia da libertação, a psicologia comunitária, a medicina comunitária, entre outras vertentes.

Seguindo ainda seu percurso de desenvolvimento, podemos situar dois grandes modelos em que se estrutura a Psicologia comunitária nos diferentes países. Conforme Góis (2005), o primeiro modelo seria o clínico-comunitário, fundamentado nas discussões empreendidas pelo movimento de saúde mental comunitária na Europa e nos Estados Unidos. O segundo modelo seria o sócio-comunitário, o qual estaria mais atrelado a uma visão sócio-política dos problemas sociais e humanos, tendo sido desenvolvido, especialmente, na América Latina.

Por esta razão, Montero (2004) afirma que, na América Latina, a psicologia comunitária tem se estruturado, principalmente, como uma psicologia social comunitária. A autora acredita que a disciplina avança da ideia de uma saúde mental na comunidade para o interesse em problemas que não são, necessariamente, compreendidos como de saúde mental, tal qual o funcionamento de indivíduos nas unidades sociais, nas organizações e nas comunidades. Vejamos, portanto, a definição que é adotada em 1982 pela teórica:

[...] o ramo da psicologia cujo objeto é o estudo dos fatores psicossociais que permitem desenvolver, fomentar e manter o controle e o poder que os indivíduos podem exercer sobre seu ambiente individual e social para solucionar problemas que os inquietam e promover mudanças nesses ambientes e na estrutura social (MONTERO, 2004, p. 70). ${ }^{6}$

Nessa definição, Montero (2004) põe em evidência a importância da promoção de mudanças por parte dos próprios indivíduos nos 
ambientes em que estes estão inseridos, sejam esses a comunidade, ou a sociedade, de maneira mais ampla. Tais mudanças devem operar no modo de enfrentar a realidade, de interpretá-la e de se relacionar com ela. Assim, a autora entende que as transformações individuais repercutiriam em transformações coletivas. Vejamos, portanto, no tópico a seguir, a articulação dessas ideias e de alguns conceitos discutidos em psicologia comunitária com a proposta da desinstitucionalização.

\section{Contribuições da Psicologia comunitária ao processo de desinstitucionalização em Saúde Mental}

Pudemos perceber, ao longo deste artigo, que a capacidade dos indivíduos se implicarem e modificarem seus contextos se configura como um assunto de grande relevância para os estudos em Psicologia Comunitária na América Latina. I gualmente ao campo teórico citado, tal capacidade é bastante abordada também em saúde, principalmente por intermédio do conceito de participação.

Desse modo, no campo da saúde, é crescente o número de estudos que se debruçam sobre o tema da participação dos usuários nos serviços (ONOCKO; FURTADO, 2008; CARVALHO, 2006; CORTES, 2002). De modo geral, esses trabalhos defendem a ideia de que a participação se constituiria em uma potente ferramenta de expressão dos segmentos excluídos da sociedade, dando voz aos anseios de uma parcela da população que não encontra representação no sistema político atual. Assim, para Onocko e Furtado (2008), "a participação é uma condição necessária a uma política social realmente comprometida com mudanças sociais, podendo ser o meio para que se previna a degradação da assistência em assistencialismo" (p. 2672).

Para garantir que isso ocorra, a Lei 8.142/90 institucionaliza a participação da comunidade na gestão do SUS na forma de duas instâncias colegiadas, expressas na Conferência de Saúde e no Conselho de Saúde. Segundo Cortes (2002), essas instâncias se configuram como os principais mecanismos participatórios do sistema de saúde brasileiro, operando "como um complemento ou como uma alternativa às formas tradicionais de representação política nas democracias liberais" (p. 19).

Em saúde mental, a participação dos usuários e da comunidade também é incessantemente requisitada. Autores como Torre e Amarante (2001) e Vasconcelos (2003, 2007, 2009), destacam que a desconstrução da cultura manicomial atinge seu sentido mais abrangente quando ocorre um processo mais amplo e complexo de participação popular. Nesse caso, a participação se configura como um espaço de construção coletiva do protagonismo que requer a 
saída do assujeitamento, de uma relação de dominação e tutela, para a constituição de um sujeito político, que debate o tratamento e sua instituição, conhece seus direitos, participa e interfere no campo político.

No entanto, entendemos que a cultura manicomial se consolidou sob a égide da racionalidade e da normatização; assim, como tomar esse tipo de participação, racional, consciente e institucionalizada sob a forma da lei, como premissa basilar para a desinstitucionalização? Pensar no louco como sujeito crítico e conhecedor dos seus direitos não seria tentar ajustá-lo ao paradigma da racionalidade?

Alverga e Dimentein (2006) podem fornecer importantes pistas para nossa reflexão. As autoras alertam para a insuficiência das perspectivas que apostam na ideia da ressocialização e reabilitação do louco, tendo em vista que os desafios impostos pela desinstitucionalização vão além da concessão de direitos sociais e não podem fundar-se na criação e ajustamento de consciências cidadãs. Nesse sentido, o ideal de uma desinstitucionalização que se proponha à desconstrução de saberes e práticas cronificadoras deve "abrir uma via de acesso à escuta qualificada da desrazão, e considerar outras rotas possíveis" (p. 303).

Nessa conjuntura, as possibilidades de participação dos usuários não podem se resumir aos espaços instituídos pelas portarias e normas que regulam tal atividade. Será preciso, portanto, que repensemos 0 conceito formal de participação, prescrito constitucionalmente, e atentemos para formas de operacionalizá-lo no cotidiano da loucura.

Vejamos como a psicologia comunitária pode auxiliar nessa reflexão. Segundo alguns autores dessa área, a participação popular é entendida como conceito também psicológico e não somente sociológico ou político (MONTERO, 2004; GÓIS, 2005; VIEIRA, 2008). Isso implica considerar que 0 ato de participar é permeado por elementos subjetivos da ordem do desejo, das percepções, dos valores, das vivências e dos sentimentos que os sujeitos constroem em sua relação com o mundo. Assim,

Decidir participar de atividades comunitárias é conseqüência de um conjunto de fatores de ordem material, afetiva e social. Muitas vezes os moradores participam porque 0 vizinho convidou, vão por amizade, identificação, ou por pensar que ali podem encontrar algo de bom para suas vidas (GÓIS, 2005, p. 192).

Nesse sentido, a participação não pode ser reduzida a uma pura colaboração que setores populacionais dão ao setor público. Pode também implicar uma participação macro política, como nas eleições e referendos, entre outras decisões coletivas, mas não se limita apenas a isso. Pode significar tomar seu lugar no espaço urbano, afetar e ser afetado pelo convívio social, fazendo a cidade e seus 
moradores experimentarem inquietações perante a diferença. Pode, ainda, ser apenas conviver, estar presente no cotidiano, relacionarse.

Para a Psicologia Comunitária da América Latina (GÓlS, 2005; MONTERO, 2003, 2004, 2006; LANE, 1996), a participação pressupõe uma relação de reconhecimento da diversidade e um processo de negociação de interesses coletivos e individuais. Segundo Vieira (2008, p. 28), "participação, portanto, pode ser compreendida como um instrumento de libertação que envolve o maior número de pessoas e um nível de importância nas decisões tomadas".

Ressaltamos tais aspectos do conceito de participação, trabalhados pela psicologia comunitária, para avançarmos na discussão sobre quais as possibilidades de participação do louco na vida social. Vasconcelos (2009) destaca que essa participação, em uma perspectiva popular-democrática, não pode se restringir aos aspectos subjetivos como decorrentes de fenômenos estritamente individuais e singulares, mas deve ser reconhecida como um processo condicionado pelo contexto sócio-histórico e cultural da sociedade e das relações sociais do sujeito. Portanto, essa participação não deve ser tratada como um projeto de um modelo ideal, mas um desvelar de experiências criativas e flexíveis, em vários contextos da vida social, em uma perspectiva emancipatória.

Por compreender as várias formas de participação das pessoas com transtorno mental, desde a participação nas atividades dos serviços de saúde mental e na comunidade, até a perspectiva do movimento social em associações de usuários e atividades de militância, Vasconcelos (2007) chama atenção para a potencialidade da vinculação aos grupos que participam:

[...] a perspectiva mais geral construída pelo movimento internacional de usuários e familiares do campo da saúde mental é propor estratégias concretas de empoderamento em níveis diferenciados de participação, complexidade e dificuldade. A maioria dos participantes pode inserir-se nos níveis mais elementares, como os grupos de ajuda e suporte mútuos, mas alguns usuários e familiares com características pessoais e culturais compatíveis e potencial de liderança poderão ser chamados a criar projetos nos níveis mais avançados ou a participar deles. Da mesma forma, quando essas pessoas se alçam a essas esferas, não devem perder de vista seus vínculos com os grupos de base e, nos casos de reincidência de uma crise psíquica, que constitui sempre uma possibilidade no campo da saúde mental, já terão seu acolhimento garantido nestes grupos (p. 180-181).

Além do conceito de participação, recorremos a outras questões discutidas em Psicologia Comunitária, as quais também nos trazem aportes para pensarmos em possibilidades de produção coletiva da 
saúde mental e efetiva desconstrução de velhas práticas manicomiais. Então, poderíamos citar um conjunto de ações que são priorizadas pela área em questão, que dizem respeito ao fortalecimento de práticas territorializadas, concernentes também ao que está preconizado para a saúde mental no contexto do SUS. Por exemplo, o estímulo a processos dialógicos e colaborativos, a construção e fortalecimento de grupos na comunidade, a construção de atividades comunitárias, a mobilização comunitária, o mapeamento psicossocial da realidade local, a identificação de potencialidades na comunidade etc.

Tais ações evidenciam uma proposta de atuação na qual o problema central "não é a relação entre saúde e enfermidade, prevenção e tratamento, mas sim a construção do morador e do psicólogo comunitário como sujeitos da realidade" (GÓIS, 2005, p. 52). Segundo esse autor, o diálogo e problematização são elementos centrais no processo transformação da realidade. "O que se busca com o diálogo (científico, técnico ou de senso comum) é a problematização do próprio conhecimento em sua relação com a realidade concreta em que se origina e/ou se destina, para compreendê-la e transformá-la solidariamente." (GÓıS, 2005, p. 110).

A Psicologia Comunitária utiliza esse conceito de problematização a partir de Freire e a define como:

Em psicologia comunitária, problematizar é gerar situações nas quais as pessoas se vêem forçadas a revisar suas ações ou opiniões acerca dos fatos de sua vida diária vistos como normais, convertidos, por tal razão, como habituais, ou percebidos como inevitáveis ao considerá-los naturais (MONTERO, 2006, p. 231). ${ }^{7}$

Sob esse prisma, a Psicologia Comunitária oferece uma boa contribuição na problematização de saberes e práticas cristalizadas sobre a saúde-doença mental junto a grupos e instituições. Por intermédio do conceito de problematização, teríamos mais uma ferramenta para a implementação da desinstitucionalização no cotidiano dos serviços e das comunidades. Dessa maneira, podemos afirmar que a problematização se oferece como instrumento de desnaturalização, que nos permite um modo de confronto com nossos próprios discursos e atitudes, uma possibilidade de desconstrução como transformação cultural, tal qual propõem Torre e Amarante (2001):

O trabalho de desconstrução do manicômio necessariamente extravasa o contexto institucional específico. A desinstitucionalização atinge então seu objetivo mais amplo de questionamento das instituições e subjetividades 
capitalísticas: é a desconstrução como transformação cultural (p. 83).

Na perspectiva em que o tema da desinstitucionalização vem sendo trabalhado, a desconstrução a que nos referimos visa a superação de paradigmas clássicos, que reproduzem concepções naturalizadas de saúde, doença, cura, normalidade. E quem sustenta estes paradigmas disciplinadores? Discutimos agora o papel dos profissionais do campo da saúde mental no processo de desinstitucionalização, onde somos chamados a inaugurar uma nova forma de relação, pois muitas vezes dizemos estar cuidando quando, na realidade, estamos exercendo custódia e controle.

Falando mais especificamente do papel da psicologia, destacamos a obra de Martín-Baró, psicólogo e padre jesuíta que morreu assassinado em 1989 por soldados do governo de El Salvador. Ele afirma que a psicologia precisa se libertar, redefinindo sua "bagagem teórica e prática, valendo-se da vida de nossos próprios povos, de seus sofrimentos, de suas aspirações e de suas lutas", (MARTínBARÓ, 2009, p. 189) buscando uma nova perspectiva e uma nova práxis.

A Psicologia da Libertação (MARTín-BARÓ, 1998) aponta para o conceito libertação e não liberdade, partindo do princípio que estamos imersos em uma realidade de povos oprimidos por regimes autoritários, miséria, marginalização e violência, desafiando a psicologia a assumir sua responsabilidade histórica no enfrentamento de um processo de mudança deste contexto. Guareschi (2009) apresenta os pressupostos epistemológicos deste conceito de Libertação: superação da dicotomia entre individual e social, a superação da dicotomia entre teoria e prática e a imprescindibilidade da dimensão ética.

Guareschi (2009) explica que os teóricos da libertação (Psicologia da Libertação, Teologia da Libertação e Pedagogia da Libertação) ao analisar os problemas teológicos, psicológicos, sociais ou educacionais, compreenderam que as raízes do subdesenvolvimento da América Latina têm como pano de fundo a necessidade de transformar as relações de dominação de um país sobre outro, que sustenta um sistema de dependência e exploração. Desta forma, a explicação dos problemas:

[...] não é mais individualizante e psicológica, é relacional e social. [...] o pressuposto era de que havia uma rede de relações que causavam o oposto da libertação, que era a opressão, a dominação. Era esse o pressuposto não apenas epistemológico, mas até mesmo ontológico, presente neste conceito: a dimensão crítica, dialética, relacional, presente na realidade "libertação" (GUARESCHI, 2009, p. 56). 
No segundo eixo epistemológico, Guareschi (2009) fala da impossibilidade de separar-se teoria e prática, pois cada conceito implica em uma prática, uma opção política, que tenha coerência e assuma as consequências de sua posição. Paulo Freire (1983) também aponta a indivisibilidade entre o que se diz e o que se faz, sendo o principal conteúdo da educação o que se pratica.

O terceiro pressuposto para Guareschi (2009) é a dimensão ética da libertação, reconhecendo que a ciência toma partido, defende valores, devendo se perguntar para que serve e para quem serve. Góis (2008) afirma que o ser livre significa sermos todos livres, sermos povos livres, assumindo um processo de construção e recriação permanente da identidade, rompendo com os valores antivida. Nesta reconstrução, segundo Touraine (2002), o sujeito emerge em sua relação com o outro, pois a consciência de si não permite o aparecimento do sujeito:

É somente quando o indivíduo sai de si mesmo e fala ao outro, não nos seus papéis, nas suas posições sociais, mas como sujeito, que ele é projetado fora do seu próprio simesmo, de suas determinações sociais, e se torna liberdade (TOURAINE, 2002, p. 239).

Somente na relação amorosa, o indivíduo deseja ser ator, superando a posição de conformidade e acomodação, deixando de ser, para Touraine (2002, p. 240), "um elemento de funcionamento do sistema social e se torna criador de si mesmo e produtor da sociedade".

Compreendemos que um dos focos da desinstitucionalização pretendida é o fomento dos processos de fortalecimento, superando a idéia da existência de um indivíduo sujeitado aos poderes disciplinares de normatização, determinado pelas forças sociais, podendo acreditar que por maiores que sejam os sofrimentos e desafios, os movimentos de resistência aparecem e uma nova relação pode ser construída sob outras bases.

\section{Conclusão}

Com efeito, a ideia de que a rede comunitária é extremamente relevante para os processos terapêuticos das pessoas com transtornos mentais tornou-se tema recorrente nas produções e discursos em Saúde Mental. Contudo, convém ainda indagarmos que entendimento nos alicerça quando destacamos o termo comunidade e como podemos trabalhar os processos que engendram a desinstitucionalização nesse âmbito.

o campo de saber da psicologia comunitária nos lembra que um princípio fundamental para a autonomia é o reconhecimento de que o cerne das decisões e dos enfrentamentos no espaço da saúde mental 
se encontra na comunidade, nos grupos, instituições e pessoas que convivem no seu entorno:

\begin{abstract}
Trata-se, de deslocar o centro de gravidade das relações sociais de fora da comunidade para o interior, de maneira que as comunidades organizadas exerçam poder e desprendam o controle necessário para realizar as transformações desejadas em seu entorno e em suas relações internas e externas (MONTERO, 2003, p. 35). ${ }^{8}$
\end{abstract}

Reconhecer a importância da comunidade na construção da saúde mental significa a emergência de novos espaços de expressão do diferente, em novas formas de pensar e sentir a realidade, desafiando sustentar a grandeza de criar modos de existência que potencializem a vida. Constitui-se numa práxis realizada por intermédio de conceitos, crenças, valores, atitudes, emoções, intenções, pensamentos e significações singulares constituídos e constituintes da cultura local. Com base nessa trama complexa feita de individualidades e coletividades, a diversidade pode ser acolhida, reconhecendo-se beleza no contraste de suas cores.

\title{
7 Referências
}

AMARANTE, P. A trajetória do pensamento crítico em saúde mental no Brasil: planejamento na desconstrução do aparato manicomial. In: KALIL, M. E. X. (Org.). Saúde mental e cidadania no contexto dos Sistemas Locais de Saúde. São Paulo-Salvador: Ed. Hucitec/ Cooperação Italiana em Saúde, 1992, p. 103-119.

. (Org.). Psiquiatria Social e reforma psiquiátrica. Rio de Janeiro: Fiocruz, 1994.

- O homem e a serpente: outras histórias para a loucura e a Psiquiatria. Rio de Janeiro: Fiocruz, 1996.

. (Org.). Saúde mental, políticas e instituições: programa de educação à distância. Rio de Janeiro: FIOTEC/FIOCRUZ, EAD/FIOCRUZ, 2003.

ALVERGA, A. R.; DIMENSTEIN, M. A reforma psiquiátrica e os desafios da desinstitucionalização da loucura. Revista Interface Comunicação, Saúde, Educação, Botucatu, v. 10, n. 20, p. 299316, jul/dez 2006.

AMORIM, A. K. A.; DIMENSTEIN, M. Desinstitucionalização em saúde mental e práticas de cuidado no contexto do serviço residencial terapêutico. Ciência e Saúde Coletiva, Rio de Janeiro, v. 14, n. 1, p. 195-204, fev. 2009. 
ARENDT, R. J. J. Psicologia Comunitária: teoria e metodologia. Psicologia: Reflexão Crítica, Porto Alegre, v. 10, n. 1, p. 7-16, 1997.

BARROS, D. D. Cidadania versus periculosidade social: a desinstitucionalização de um saber. In: AMARANTE, P. (Org.).

Psiquiatria Social e reforma psiquiátrica. Rio de Janeiro: Ed. Fiocruz, 1994, p. 171-195.

BASAGLIA, F. A destruição do hospital psiquiátrico como lugar de institucionalização: mortificação e liberdade do "espaço fechado".

In: AMARANTE, P. (Org.). Escritos selecionados em saúde mental e reforma psiquiátrica. Rio de Janeiro: Garamond, 2005, p. 23-34.

BAUMANN, Z. Comunidade: a busca por segurança no mundo atual. Rio de Janeiro: Jorge Zahar, 2003.

BIRMAN, J.; COSTA, J. F. Organização de instituições para uma Psiquiatria Comunitária. In: AMARANTE, P. (Org.). Psiquiatria Social e reforma psiquiátrica. Rio de Janeiro: Ed. Fiocruz, 1994, p. 41-72.

BRASIL. Sistema Único de Saúde. Conselho Nacional de Saúde. Comissão Organizadora da III CNSM. Relatório final da III Conferência Nacional de Saúde Mental. Brasília, 2002.

CARVAlHO, G. C. M. Participação da comunidade na saúde. Passo Fundo: IFIBE; CEAP, 2007.

CORTES, S. M. V. Construindo a possibilidade da participação dos usuários: conselhos e conferências no Sistema Único de Saúde. Revista Sociologias, Porto Alegre, ano 4, n. 7, p. 18-49, jan./jun. 2002.

GÓIS, C. W. L. Psicologia Comunitária: atividade e consciência. Fortaleza: Publicações Instituto Paulo Freire de Estudos Psicossociais, 2005.

Hucitec, 2008.

Saúde comunitária: pensar e fazer. São Paulo: Editora

GUARESCHI, P. A. Pressupostos epistemológicos implícitos no conceito de libertação. In: GUZZO, R. S. L.; LACERDA J r., F. (Orgs.). Social para América Latina: o resgate da Psicologia da libertação. São Paulo: Ed. Alínea, 2009, p. 49-64.

LANCETTI, A. Prevenção, preservação e progresso em saúde mental. In: Saúde loucura 1. São Paulo: HUCITEC, 1989, p. 75-89. LANE, S. T. M. Histórico e fundamentos da Psicologia Comunitária no Brasil. In: FREITAS, Campos et al. Psicologia Social Comunitária: da solidariedade à autonomía. Rio de Janeiro: Vozes, 1996, p. 17-34. MARTIN-BARÓ, I. Psicología de la liberación. Madrid: Editorial Trota, 1998.

- Para uma Psicologia da libertação. In: GUZZO, R. S. L.; LACERDA J r., F. (Orgs.). Psicologia Social para América Latina: o 
resgate da Psicologia da libertação. São Paulo: Ed. Alínea, 2009, p. 189-198.

MENEZES, M.; YASUI, S. O psiquiatra na atenção psicossocial: entre o luto e a liberdade. Ciência Saúde Coletiva, Rio de Janeiro, v. 14, n. 1, p. 217-226, fev. 2009.

MONTERO, M. Teoría y práctica de la Psicología Comunitaria: la tensión entre comunidad y sociedad. Buenos Aires: Paidós, 2003.

Introducción a la Psicología Comunitaria: desarollo, conceptos y procesos. Buenos Aires: Paidós, 2004.

Hacer para transformar: el método en la Psicología Comunitária. Buenos Aires: Paidós, 2006.

OLIVEIRA, A. G. B.; ALESSI, N. P. Cidadania: instrumento e finalidade do processo de trabalho na reforma psiquiátrica. Ciência e Saúde Coletiva, Rio de Janeiro, v. 10, n. 1, mar. 2005.

ONOCKO-CAMPOS, R. T.; FURTADO, J. P. Entre a saúde coletiva e a saúde mental: um instrumental metodológico para avaliação da rede de Centros de Atenção Psicossocial (CAPS) do Sistema Único de Saúde. Revista Cadernos de Saúde Pública, Rio de Janeiro, v. 22, n. 5, p. 1053-1062, maio 2006.

Participação, produção de conhecimento e pesquisa avaliativa: a inserção de diferentes atores em uma investigação em saúde mental. Revista Cadernos de Saúde Pública, Rio de Janeiro, v. 24, n. 11, p. 2671-2680, novembro 2008.

ORGANIZAÇÃO MUNDIAL DE SAÚDE. Carta de Ottawa, 1986. Disponível

em:

<http://www. opas. org.br/promocao/uploadArq/Otawa.pdf>. Acesso em: 25 set. 2008.

PAIVA, I. Em defesa da reforma psiquiátrica: por um amanhã que há de renascer sem pedir licença. 2003. 165f. Dissertação (Mestrado em Psicologia) - Programa de Pós-Graduação em Psicologia, Universidade Federal do Rio Grande do Norte, Natal, 2003.

PEREIRA, W. C. C. Nas trilhas do trabalho comunitário e social: teoria, método e prática. Belo Horizonte: Vozes/PUC Minas, 2001.

ROTELLI, F. Superando o manicômio: o circuito psiquiátrico de Trieste. In: AMARANTE, P. Psiquiatria Social e reforma psiquiátrica. Rio de Janeiro: Fiocruz, 1994, p. 149-169.

Desinstitucionalização, uma outra via. In: ROTELLI, F.; LEONARDIS, O.; MAURI, D. (Orgs.). Desinstitucionalização. São Paulo: Ed. Hucitec, 2001, p. 17- 59.

SAWAIA, B. B. Comunidade: a apropriação científica de um conceito tão antigo quanto a humanidade. In:

Psicologia Social

Comunitária: da solidariedade à autonomia. Petrópolis: Vozes, 1996, p. 35-53.

TORRE, E. H. G.; AMARANTE, P. Protagonismo e subjetividade: a construção coletiva no campo da saúde mental. Ciência e Saúde Coletiva, Rio de Janeiro, v. 6, n. 1, p. 73-85, 2001. 
TOURAINE, A. Crítica da modernidade. Petrópolis, RJ : Vozes, 2002. VASCONCELOS, E. M. O poder que brota da dor e da opressão: empowerment, sua história, teorias e estratégias. São Paulo: Editora Paulus, 2003.

- Dispositivos associativos de luta e empoderamento de usuários, familiares e trabalhadores em saúde mental no Brasil. Vivência (Natal), v. 32, p. 173-206, 2007.

Abordagens psicossociais I: história, teoria e trabalho no campo. 2. ed. São Paulo: Editora Hucitec, 2009

VIEIRA, Emanuel M. Atividade comunitária e conscientização: uma investigação a partir dos modos de participação social. 2008. 125f. Dissertação (Mestrado em Psicologia) - Programa de PósGraduação em Psicologia, Universidade Federal do Ceará, Fortaleza, 2008.

\section{Endereços para correspondência Dayane Silva Rodrigues}

EPTG QE 04, BL B14, APTO 302, Bairro Lúcio Costa, Guará-DF, Brasil. CEP: 71100179.

Endereço eletrônico: dayanesr@yahoo.com.br

Maria Aparecida Alves Sobreira de Carvalho

Rua Sady Fernandes de Aragão, no 14, apartamento 101, Bairro Gato Preto. CEP 58802-030, Sousa- PB, Brasil.

Endereço eletrônico: apsobreira1@hotmail.com

\section{Verônica Morais Ximenes}

Av. Santos Dumont, 7000/903, BI. A, Bairro Papicu, CEP 60190-800, Fortaleza CE, Brasil.

Endereço eletrônico: vemorais@yahoo.com.br

Recebido em: 05/02/2010

Reformulado em: 09/07/2010

Aceito para publicação em: 09/07/2010

Acompanhamento do processo editorial: Adriana Benevides Soares

\section{Notas}

* Mestre em Psicologia pela Universidade Federal do Ceará (UFC). Especialista em Assistência Social da Secretaria da Criança do Governo do Distrito Federal.

** Mestre em Psicologia pela Universidade Federal do Ceará (UFC). Professora do Instituto Federal de Educação, Ciência e Tecnologia da Paraíba- Campus Sousa.

*** Professora Adjunto do Departamento de Psicologia da Universidade Federal do Ceará (UFC), Docente da Graduação e da Pós-Graduação em Psicologia da UFC, Coordenadora do Núcleo de Psicologia Comunitária (NUCOM) da UFC. Doutora em Psicologia (Universidade de Barcelona).

${ }^{1}$ Agradecimentos: Este estudo foi financiado pelo Edital MCT/CNPq/CTSaúde/MS/SCTIE/DECIT 033/2008 e pela CAPES (bolsa de Mestrado Demanda Social), pelo que agradecemos imensamente o apoio.

${ }^{2} \mathrm{Em}$ 1990, na cidade de Caracas ocorreu um marco histórico para a Saúde Mental, por ocasião da realização da Conferência Regional para Reestruturação da Assistência Psiquiátrica. Neste evento, que contou com a participação do Brasil e 
Dayane Silva Rodrigues, Maria Aparecida Alves Sobreira de Carvalho, Verônica Morais Ximenes A comunidade como espaço de produção de saúde mental

diversos países, foi promulgado o documento "Declaração de Caracas", onde os países se comprometiam a promover a reestruturação da assistência psiquiátrica, rever criticamente o papel hegemônico do hospital psiquiátrico, resguardar os direitos civis das pessoas com transtornos mentais, sua dignidade pessoal e direitos humanos, bem como, favorecer uma rede de atenção à saúde mental na comunidade.

${ }^{3}$ A Psicologia Comunitária da América Latina surge do processo de crise e transformação da Psicologia Social que se desenvolvia em meados da década de 1970 e 1980, a partir dos questionamentos acerca da conexão dos trabalhos e da produção científica da Psicologia com o nosso contexto. No Brasil, somente na década de 1980 passa a ser considerada de fato uma Psicologia e não outra disciplina da área social ou um mero trabalho político-partidário. Assim, nos anos noventa consolida-se como profissão e o que pudemos assistir desde essa época foi o desenvolvimento de uma diversidade epistemológica, teórica e metodológica na área. Diante de tamanha pluralidade, vale situar que, neste artigo, quando mencionamos o termo Psicologia Comunitária, empregamos as compreensões de autores como: Góis, 2005; Montero, 2003, 2004, 2006 e Lane, 1996.

${ }^{4}$ A Psicologia Comunitária definida por Góis (2005) tem como marcos teóricometodológicos: Psicologia da Libertação, Pedagogia da Libertação, Psicologia Histórico-Cultural, Biodança e Teoria Rogeriana.

${ }^{5}$ Tradução nossa.

${ }^{6}$ Tradução nossa.

${ }^{7}$ Tradução nossa.

${ }^{8}$ Tradução nossa. 